\title{
LandMark: Dance as a Site of Intertwining
}

Jane Carr University of Bedfordshire

\begin{abstract}
In the performance installation, LandMark (2011), dancers Deborah Saxon and Henry Montes and the visual artist Bruce Sharp explore both the facticity of human experience and the frailty of connections between people and between them and the world they inhabit. ${ }^{1}$ I suggest their work may also be understood to probe the complexities of the interrelationships between consciousnessworld and self- other that are the focus of Maurice Merleau- Ponty's text, The Intertwining-The Chiasm (1968). His analysis of intercorporeality is particularly relevant to understanding the significance of the dancers' somatic investigations that inform their artistic practices. Further, by drawing on developments upon Merleau-Ponty’s work in ecological aesthetics (Crowther, 1992) and social philosophy (Maclaren, 2002), I explore how the artists' creative practices may be understood to foster intercorporeal negotiations of significance. This is suggested to be of increasing importance within an intracultural context in which people have a complex variety of cultural experiences even while sharing in a national identity.
\end{abstract}

\section{Key Words}

Dance, Ecological Aesthetics, Intercorporeality, Intracultural, Installation, Siobhan Davies, Henry Montes, Deborah Saxon, Bruce Sharp,

\section{Introduction}

LandMark (2011) was created by dancers Deborah Saxon and Henry Montes in collaboration with the visual artist Bruce Sharp for the Siobhan Davies Commissions at the Bargehouse gallery. (See figure 1). Part installation, part performance, for dance critic Katerina Pantiledes (2011) the work 'successfully 
conveys both the arbitrary nature of memory and the sense of fulfilment inherent in making moving narratives from fragments'. I will suggest further that in LandMark the artists reveal something of the complexities of the interrelationships between consciousness- world and self- other that are the focus of the existential phenomenology of Maurice Merleau- Ponty.

In pursuing this inquiry my aim is in part to demonstrate why Merleau-Ponty's posthumous, unfinished text The Intertwining-The Chiasm (1968) is, even after over thirty years since his death, relevant to the concerns of many dance artists in its innovative approach to the relationship between conscious awareness and the physical world. Drawing on developments of Merleau-Ponty's philosophy in the fields of philosophical aesthetics and social philosophy, I further suggest how some current dance practices, such as those informing LandMark, foster sensitivities and skills that provide the capacity for the intercorporeal negotiation of significance across difference. Such practices, I argue, may prove fruitful in the process of dance performance making within intracultural contexts understood as comprising of people with different cultural experiences and values who nevertheless belong to the same national group. ${ }^{2}$

In what follows I will be reflecting upon my findings from interviews with the artists in the initial rehearsal phase (Deborah Saxon, $6^{\text {th }}$ May 2011, Henry Montes $11^{\text {th }}$ June 2011, Bruce Sharp $9^{\text {th }}$ July 2011, interviews) and towards the end of a week of performances (Montes, Saxon and Sharp 11 ${ }^{\text {th }}$ September 2011, interview). I also observed some early studio rehearsals on video and draw on my phenomenological experiences of the work in rehearsal and performance in the gallery space, together with further analysis of video documentation of performances and a final interview with one of the artists (Bruce Sharp 29 ${ }^{\text {th }}$ March 2012, interview). It is, important to state at the outset that, the artists did not set out to represent philosophical concepts. Nor, did they aim to create a piece of intracultural performance, although as artists born in the UK, Australia 
and America, working collaboratively in London their work is informed by the experience of cultural diversity. ${ }^{3}$ Rather this synthesis of research into their working practices and the phenomenology of Maurice Merleau-Ponty is a product of my interdisciplinary approach to researching the significance of dance that is informed by my own experiences as a dancer, choreographer, dance teacher and audience member.

The interdisciplinary research method I have developed draws on some interviewing and observation techniques more generally associated with dance ethnography. However this research should not be read as dance ethnography that supports philosophical reflections upon the significance of dance or vice versa. Rather in developing a framework for interdisciplinary research, reflections from different perspectives inform one another. As the dance anthropologist, Andrée Grau (1992), has observed, the point of interdisciplinary research is not to work from the basis of one subject area, bringing two or three others into it, but to create something new. Hence reflecting back (in the phenomenological sense) on my experience of the performance events informed my re-reading of the philosophy of Merleau-Ponty (1968) as much as my prior theoretical interest in phenomenology and embodiment, along with interviews with the artists, inevitably shaped my (phenomenological) engagement with the work in performance. The importance of such reflexivity is recognised in many ethnographic studies. Charlotte Aull Davies, for instance, argues for an ethnographic approach that 'embraces its intrinsic multi-layered reflexivity without turning inward to complete self-absorption' (Aull Davies, 1999: 25). ${ }^{4}$ One means of guarding against such self- absorption is the dialectical anthropology developed by the anthropologist John Blacking in which 'there is an exchange between analysts and informants which brings into play two kinds of technical knowledge and experience, and in which informants share the intellectual process of analysis' (Grau, 1992: 5-6). It was thus important to my 
research process to ensure that the artists involved engaged with me seriously in discussions and read drafts of my writing, providing feedback that further informed my reflections and the final text.

Nervertheless, I am mindful that in the process of writing and rewriting this text for publication, the sense I have made about LandMark is situated within academic discourses that lead me to only one of many possible interpretations. Yet, from the perspective of an ecological aesthetics as developed by Paul Crowther (1993), that draws strongly on the influence of Merleau-Ponty, I perceive the process of sharing exploration of the significance of an artwork as an important part of the field within which it is experienced and understood as art.

\section{Choreographic Investigations}

The initial inspiration for LandMark was an exhibition of the photographs of William Eggleston at the Victoria Miro gallery. For the dance artists Deborah Saxon and Henry Montes, a sense of the relationship between living spaces and their (absent) residents revealed the lingering facticity of presence. Yet, as Montes stated, Egglestone's evocative images also suggest how, through time, 'what is left behind takes on a different significance' (Montes, 11th April, 2011, interview). Montes was also struck by the plight of those whose homes had been so totally destroyed by the Australian bush fires that they had lost all traces of their previous existence. He recognised how they 'were unable to grieve or have closure...because there were no remains, as if the houses had never been there' (Montes, personal email communication $16^{\text {th }}$ February, 2014). From these starting points the dancers became interested in the interrelationship between action, memory and place. This informed their initial choreographic explorations into the associative connections that provide the glue binding 
together coherent narratives of past experience. Through their movement investigations the dancers worked to suggest both the interrelationship of the senses in the act of remembering and, at the same time, how the traces of the past can become disassembled and reconstituted. Many dancers practice techniques such as Alexander (which Montes teaches) and Feldenkrais, which require the development of an enhanced awareness of their actions so that dancers can consciously make small changes to their movements. Often their aim is to undo movement habits that affect the functional efficiency and quality of their actions in order to cultivate more kinesiologically efficient ones. However, in LandMark, this process of disassembling and reassembling rarely results in the seamless flow of 'organic' movement that is often associated with the dancing of artists trained in these techniques. Rather Montes and Saxon perform fragments of actions, often repeating them as if to fathom their somatic experience to capture how the movements connect to each other. As Montes repeats a breath followed by gestures of the arms he seem to be in the process of figuring out his sense of relationship to the actions that initiate his arm movements. In such moments the dancers' explorations of their own movement suggest something of the complexity of the relationship between conscious somatic experience and a sense of self.

Exploration of the use of vocal sounds in rehearsal led the dancers to realise how, using repetition, they could create associations between movement fragments and the sounds they made. Initially creating movement that 'saturates' the space, their intention was to produce a strong relationship between movement and a simple sound such as whistling that, impressing itself into the experience of the audience, creates a tension between the continuing sound and the visual impact when a new, different, movement is performed.

Other creative strategies that also mine this sense of disjuncture lead to Saxon making a strange half whine, half sob while performing a curious wiggling of 
the hips and to Montes setting himself coughing to the point of choking while attempting to complete a series of gestural actions set in counterpoint to the rhythmic spasms of his chest. (See figure 2). This coughing dance seems to further interrogate the relationship between consciousness and motor systems, channelling attention towards the complex interrelationship between reflex actions, habits and learned gestures. In this way Montes brings into focus the play between the physical and social demands of human existence that raises questions regarding the relationship between seemingly automatic bodily systems, conscious awareness, and culturally ingrained habits.

The sense of how consciousness and world intersect is further enhanced by situating the recurring, durational performance within the artist Bruce Sharp's installation of flicker books that he created in response to the dancers' rehearsals. Suspended downwards, hanging off filaments of thread, they intersect the space, bringing both dancers and audience into a direct relationship with the artist's responses to the dancers' previous actions. Sourced from both video recordings and Sharp's observations of the dancers, some books are cinematic, capturing Saxon crawling or Montes gesturing, others reveal rather more curious responses that punctuate both the space and the consciousness of those onlookers who momentarily flick through them. Saxon aimed for the books to provide 'pockets of images' that are, in themselves, traces of the imagination or 'ripples of thought' (Saxon, 6th May 2011, interview) that make manifest the artist's consciousness in responding to the dance. On reflection, Sharp envisages the books as providing 'bridges between different moments of being' and as 'holding time' (Sharp, 29th March 2012, interview). ${ }^{5}$ Sharp also collected sounds from the dancers and the site that were added to the installation to emphasise the sense of how past and present seem to coalesce in the viscosity of the inhabited space. 
For the dancers, the installation and the gallery environment itself posed challenges. The space at the Bargehouse is open and expansive with large windows letting in light and a sense of the world beyond; while in the peeling paint and rough surfaces of the walls, the past has left its tangible imprint. In combination with the presence of the flicker books, this environment was one within which the dancers found some of the subtle plays between movement and sound, that had worked in a small studio setting, failed to make an effect. The dancers had created movement fragments that allowed for a certain improvisatory flexibility, but in the short period that they could rehearse with the installation they had to rework aspects of the choreographic structure in response to this new context. However, as the dancers continued to work into the space, the work came to life so that the dancers' experience of working in the installation not only informed planned decisions to make small changes but informed their responses to one another and the space in performance. Where previously, Sharp responded to the dancers in making the flicker book installation, in performance the dancers' actions are informed by the space which contains an overlapping of their own (invisible) memories with those captured (visibly) on paper. That the audience are free to come and go and to interact with the installation adds another layer of interactions as does Sharp's continual adjustments to the sound in response to activity in the space.

\section{Rethinking Consciousness- World and Self-Other}

In creating LandMark the artists' explorations of the relationship between consciousness and the physical world seem to me to parallel Merleau-Ponty's philosophical investigations in the posthumously published The IntertwiningThe Chiasm (1968). His starting point, the ‘doubleness' of bodily being as both object in the world and subject sensing the world, is a perspective that is particularly fruitful for dancers for whom understanding this relationship is an important part of their skills as performers. Merleau-Ponty's recognition of the 
'double nature of the body as a thing among things' (Merleau-Ponty, 1968:143) that is also the source of what is seen and touched, leads him to describe an intertwining of consciousness and world demanding we 'reject the age old assumptions that put the body in the world and the seer in the body' (1968: 138). In this challenge to Cartesian dualism he also reconsiders the phenomenological problem of the relationship between the body as object (in itself in phenomenological terms, or a thing to be sensed by others) and the body as subject (for itself, or as a sentient being). Arguing against the gulf between consciousness and the physical world that haunts the phenomenology of his fellow philosopher Jean Paul Sartre (Moreland, 1998), Merleau-Ponty suggests how the senses bring humans into a kind of 'participation in' and 'kinship with' the visible world (1968: 138).

Merleau-Ponty's analysis of the sensing-sensed self further leads him to an exploration of a multiplicity of interrelationships between vision, touch and hearing, between each of the senses and the world and between sentient-sensible beings. This investigation of the reversibility of, and interrelations, between sensation, cognition and language develops into his concept of an elemental but immaterial 'flesh' that is not matter but:

...the coiling over of the visible upon the seeing body, of the tangible upon the touching body..... this pact between them and me according to which I lend them my body in order that they inscribe upon it and give me their resemblance, this fold, this central cavity of the visible which is my vision, these two mirror arguments of the seeing and the visible, the touching and the touched, form a close bond system that I count on, define a vision in general and a constant style of visibility from which I cannot detach myself. 
In a radical decentring of consciousness, Merleau-Ponty argues against a philosophical legacy in which the individual thinking subject is a 'centrifugal unity of a multitude of 'consciousness of'. Rather he considers the ways in which physical being may be experienced as woven into the fabric of a feelingthinking world and to argue for the dependency of thinking upon feeling (Merleau-Ponty, 1968: 146).

In general terms, there may be parallels between Merleau-Ponty's philosophical explorations and more recent research that suggests how it is necessary to develop a way of thinking about the neural bases of perception and action that does not rest on the assumption that the brain is the seat of consciousness. For example, Kevin O’ Regan and Alva Noë propose a 'sensorimotor' account of the differences between the senses in which each may be viewed as a 'mode of exploration' that is mediated by knowledge of what they term 'sensorimotor contingencies' (O’ Regan and Noë, 2001: 940). For O’ Regan and Noë how we experience seeing, touching or hearing as qualitatively different from one another is not governed by differences in the neurons in the brain that receive the information but by the differences in structural relations between action and changes in sensory perception. Their focus is thus on how people exercise looking, touching and hearing in response to the world. Particularly pertinent in this context is O' Regan's finding of how (in contrast to traditional models of visual representation) the outside world acts as an 'outside memory' ( $O$ ' Regan and Noë, 2001: 946). Such a concept may provide for what is an extraordinary moment in some performances of LandMark when Saxon seems to search around her own body to pull out a small object. (See figure 3). Upon retrieving a spoon or a scrap of paper, she inspects it quizzically as if trying to recall its significance in the sequences of actions that constitute her world. Here in a short, simple action she suggests the enormity of that sense of lack when a lived 
connection to the world, and hence the memories contained within a sphere of experience, is lost.

Merleau-Ponty's philosophy also informs understanding of the importance of the intercorporeal relationships upon which such performance depends. For Merleau-Ponty there is a qualitative difference in perceiving the world if we share that experience with another person arguing that 'it is not I who sees, not he who sees, because an anonymous visibility inhabits both of us' (MerleauPonty, 1968:142). LandMark, might be seen as proposing such a realm of intertwining or intercorporeal transitivity. Where Merleau-Ponty posits 'a presumptive domain of the visible and the tangible, which extends further than the things I touch and see at present' (Merleau-Ponty, 1968:143), the dancers inhabit a realm which seems to contain the traces of their many years of dancing together, both in the works of Siobhan Davies and their own choreographies. In this shared space, the dancers' memories extend beyond self to the other to allow for the ease with which they are able to take over what Saxon describes as the 'residues' of each other's movement as they respond to one another's actions and sounds (6 $6^{\text {th }}$ May 2011, interview). This sense of a shared history, however also imbues moments of disrupted connection between the dancers, or between the dancers and their own bodies. Saxon and Montes mine that experience of dislocation that is only possible in the context of a previous familiarity: in one fragment, Montes grabs Saxon's thighs and she gently places his hands back on his own legs before both dancers turn away, only to then retrace their steps to repeat the action as if they are continuously reremembering a moment of separation. (See figure 4). At other times the dancers seem lost to themselves and to each other: Saxon can be seen searching her own body while elsewhere Montes seems unable to catch his last step. Such moments may serve as reminders of how Merleau-Ponty's analysis of intercorporeal transitivity never slips into an easy dissolving of boundaries 
between self-other. Rather he explores a sense of divergence that affects not only the relationship between self-other but our own grasping of ourselves that is never quite complete.

One of the criticisms of Merleau-Ponty is that he seems to provide little acknowledgement of difference: for example in describing his concept of flesh he states:

...there is even an inscription of the touching in the visible, of the seeing in the tangible-and the converse; there is finally a propagation of these exchanges to all bodies of the same type and of the same style which I see and touch.

(Merleau-Ponty, 1968: 143)

It is this reciprocity that, for Merleau-Ponty, 'founds transitivity from one body to another' (Merleau-Ponty, 1968: 143). Yet, in a contemporary context questions may be raised regarding just how, what and why bodies are understood to be 'of the same type' or by default designated as 'different'. That Merleau-Ponty failed to recognise the unequal positioning of male and female is the subject of feminist critique (Butler, 2008), and similar questions might be raised in relation to differences in terms of ethnicity, age and (dis)ability. Hence in drawing on his existential phenomenology within a context in which intercultural and intracultural exchanges are increasingly important, it is necessary to recognise the inequalities that frame how those interactions take place. $^{7}$

However, in contrast to a focus on Merleau-Ponty's seeming indifference to difference, his resistance to a simple binary conceptualisation of self-other may rather be considered to allow for exploration of the complexities of exchanges, not only between different people but also between the sensing-sensed self. 
Recognition that neither subject nor object is ever fully grasped provides for the relationship between self-other to remain fluid - just as the identity of the self can never quite be fully recognised. This instability suggests a potential for the re- negotiation of identities that is important to those concerned with difference. ${ }^{8}$ In the processes of both the creation and performance of dance, what I think is worth exploring is how the intercorporeal negotiation of difference may be either inhibited or facilitated. Here, it is important to consider the role of kinaesthesia. ${ }^{9}$ While the perceptual systems that provide for kinaesthetic sensations are dependent upon human biology, they are also a product of the environment and thus culturally shaped. The dance ethnographer, Deidre Sklar argues that the 'dynamic contours' of movement are 'critical to 'memories of movement, to communication via movement and to the cultural knowledge and values communicated through movement' (Sklar, 2008: 88). Kinaesthetic awareness is structured into patterns of physical sensation that become part of cultural conscious so that to some extent, kinaesthetic patterns are absorbed and understood tacitly as part of culture. Hence people's actions may be shaped by their culture without their being fully aware of this and, as in the experience of 'kinaesthetic empathy', they may respond to the dynamic content of someone's actions without always being able to articulate quite why. ${ }^{10}$ Dance artists may aim to open up to scrutiny the norms embodied in movement through choreographic strategies that focus attention on kinaesthetic expectations. Hence repetition of actions, unexpected changes to the flow of movement, variations to the sound environment and movements that emphasise a visceral discomfort (all of which occur in Landmark) may play a role in disrupting the audience's kinaesthetic response and this may inform the process of the intercorporeal negotiation of the significance of the work.

For dancers it is a notable exception that while in The Intertwining MerleauPonty is interested in the sensation of touch, he does not explore kinaesthesia. 
Further, as both Maxine Sheets-Johnstone (2008) and Richard Shusterman (2009) point out, in his earlier work he denies the relevance of examining the (felt) relationship between decision and bodily movement claiming, in relationship to his own body, 'I have no need to look for it, it is already with me' (1968: 108). ${ }^{11}$ However, in this earlier text Merleau-Ponty seems to be arguing against an analysis of the (kinaesthetic) perception of the body purely as the object of an individual's own inner consciousness. For artists concerned to 'look for' the body, this may serve as a reminder that their exploration is already part of their intercorporeal experience. This is something I consider to be important to an ecological aesthetics of dance in which significance is dependent on the interactions of performers and audience.

\section{Ecological Aesthetics}

My own observations suggest some of the audience struggle to make sense of LandMark while others are able to engage with the work on their own terms, perhaps flicking through a book and then pausing to watch the dancers before continuing. For Sharp, the tactile quality of the flicker books is aimed at encouraging a sense of physical interaction with the work. He makes a distinction between those who respond corporeally to the environment and those who remain detached observers (Montes, Saxon and Sharp, 11th September, 2011, interview). The dancers are also aware of how the presence of the spectators changes their experience of the space and their actions within it. For example, Montes and Saxon are concerned that when a number of people focus on their actions they sense certain sections become 'theatrical' in a manner which they feel is detrimental to the performance. However the dancers also seem concerned if they sense a lack of audience engagement, reporting that it is hard work to retain a focus on their actions and to stay 'connected' to the work (Montes, Saxon and Sharp, 11th September, 2011, interview). In performance they are able to respond to their sense of the audience, for instance 
cutting short a moment that might become too 'theatrical' or at other times, especially when the space becomes crowded with audience, intensifying their performance so that their actions punctuate the busy space.

The experience of dancers in response to spectators has often been explored in relation to the power of the gaze which objectifies the person being looked at. Such approaches often reference Laura Mulvey's account of the male gaze in which 'pleasure in looking has been split between active/male and passive/female' (Mulvey, 1975: 11). However, it has been suggested by Ann Cooper Albright (1997:15) that not all dance positions the performers in this manner. Merleau- Ponty's theorisation of the interrelatedness of self-otherworld offers an alternative framework for considering the interaction between performers and between performers and spectator. Such a perspective may emphasise how the particular dynamics of the relationship between performer and audience within a shared space affect experience of the work.

Consideration of the interrelationships between performer and audience may further be thought of as important to the development of an ecological aesthetics of dance. Drawing on the phenomenology of Merleau-Ponty within the framework of traditional aesthetics, Paul Crowther (1993) has developed an aesthetic theory that foregrounds human embodiment in the context of continual reciprocal interactions. On Crowther's terms the artist, or in the case of collaborative works, artists, being caught up in a web of reciprocal relationships ensures that their work reflect modes of 'embodied inherence in the world' (Crowther, 1993: 7) thus extending further than their individual understanding. Further, to appreciate art is itself an embodied act. By exploring how, in responding to an art work, we become part of a shared ecology, Crowther emphasizes the importance of attempting to understand what others value (Crowther, 1993, 199-200) and, while recognising the difficulties in sharing 
agreement with regard to experiences of art, he argues for the significance of such efforts.

While Crowther does not apply his aesthetic philosophy to dance, the dance theorist Bonnie Rowell (2009) has drawn upon Crowther's concept of embodiment to describe how the dancer's subjectivity becomes part of what is embodied in a dance work. In my previous research towards PhD (Carr, 2008), I also recognised the importance of his ecological approach to the appreciation of dance within the current context of increasing cultural diversity. Further, I have suggested that Crowther's investigation of the reciprocal relationships that we enter into in engaging with art can be developed to consider the complexities of intercorporeal interactions between choreographer, performers and audience that take place in preparation for and during a dance performance (Carr, 2013). Hence, the potential of dance to stimulate intercorporeal exchange may be viewed as an important element contributing to the negotiation of the significance of a work.

The processes of intercorporeal engagement in relation to dance may be further examined in the terms the philosopher Kym Maclaren (2002) uses to describe what, for her, are the implications of Merleau- Ponty's later work for interpersonal interactions in a general social context. She brings to attention the sense in which through intercorporeal engagement with others, people can experience different styles of being. However, she is careful here not to slip into an interpretation of intercorporeality that provides for total identification between self and other but rather explores an arena of 'indistinction between two bodies' drawing on Merleau-Ponty's notion of écart which she describes as being 'there' in the actions of the others and at the same time 'here' following them (Maclaren, 2002:192). She then moves on to explore the complex play of intercorporeality and intersubjectivity that allows for what she describes as the capacity for ' letting others be’ Maclaren, 2002:192). Maclaren pays attention to 
how, in interactions with others, very often one person may feel they have been positioned in a manner that is not comfortable for them. She explores how such experiences may instigate transformation into other styles of being as a response that facilitates both parties to find a means of 'letting others be' (Maclaren, 2002198). As a philosopher, Maclaren does not venture far into questions of how such interactions are part of a social realm in which there may be inequalities in terms of capacities to act; nor does she consider the dynamics of the relationship between audience and performer. Nonetheless, if her analysis of interpersonal interactions is developed within an interdisciplinary approach to dance performance, it is possible to consider how the reciprocal interactions between artists and between them the audience and the performance environment, inform the experience of the work. Dance works that challenge audiences' kinaesthetic expectations may not always be easy, either to perform or watch, but may engender intercorporeal negotiations that have the potential to lead to transformation.

In LandMark, through corporeal interactions with the installation, the changing audience and each other, the dancers maintain a responsiveness that fosters changes in their actions. While for their audience the work draws on their capacity to engage reciprocally with the fragments with which they are presented. The work is not self consciously intracultural but its creation is the result of interactions between three people who in many ways (that are not restricted to ethnicity and cultural background), are very different. By placing the work in a London gallery the artists understand the audience will be varied in terms of ethnicities and cultures, in addition to other aspects of difference , and that it is important to foster a multiplicity of ways of 'entering' into the work (Sharp, interview 29 $9^{\text {th }}$ March 2012). An ecological aesthetics that recognises the intercorporeal negotiation of significance may provide a framework for a shared sense of artistic engagement that, however, does not 
ignore the increasingly intracultural dimension to the engagement with dance and recognises the difficulties and inconsistencies that are part of this process.

\section{Conclusion}

In a context in which the experience of a stable, shared world cannot be taken for granted, the fraility of the connections that bind experience together is what LandMark makes evident. At the same time LandMark suggests the facticity of a shared realm in which, as Merleau-Ponty explores, we are never able completely to grasp ourselves nor separate ourselves from the world around us and those with whom it is shared. In LandMark the dancers investigate the experience of connection (and disconnection) of consciousness to both a sense of self and to the world around them. While Sharp's installation emphasises how the environment within which they move holds traces of their past actions. I have further suggested that Merleau-Ponty's analysis of intercorpeality supports understanding of how an acquired sensitivity to the reciprocity of being in the world informs the dancers' skills, not only in their responses to one another but also to their audience and to the environment in which they perform. While for the audience, engagement with the dancers' explorations of somatic experience, may inform (even challenge) their own consciousness of being in the world. The potential for such responsive sensitivity may be of increasing importance to artists working in a rapidly changing social realm who aim to create work, the significance of which, while never fully shared, is available to a process of intercorporeal negotiation across difference This process may be understood as important within the framework of an ecological aesthetics that is particularly valuable within intracultural contexts. Yet, if artists and audiences are to engage successfully with one another across difference they may need equally to strive to develop the skill of 'letting others be'. 


\section{Works Cited}

Bharucha, R. (996) ‘Somebody’s Other’ in Pavis, P. (ed.) The Intercultural Performance Reader, London: Routledge, pp.196-216.

Bharucha, R. (1997) 'Negotiating the "River": Intercultural Interactions and Interventions', The Drama Review, 41:3(Autumn) pp. 31-38.

Butler, J. (2005) 'Merleau-Ponty and the Touch of Malebranche', in T.Carman, and M. Hansen (eds.) The Cambridge Companion to Merleau-Ponty, Cambridge: Cambridge University Press.

Butler, J. (2008) 'Sexual Difference as a Question of Ethics: Alterities of the Flesh in Irigaray and Merleau-Ponty', Chiasmi International, 10, pp.333-347.

Carr, D.J. (2008) 'Embodiment, Appreciation and Dance: Issues in relation to an exploration of the experiences of London based, 'non-aligned' artists', unpublished thesis, London: University of Roehampton,http:// roehampton.openrepository.com/roehampton/bitstream/10142/47593/1 3/openning.pdf.

Carr, J. (2013) 'Embodiment and Dance: Puzzles of Consciousness and Agency ' in J. Bunker, A. Pakes and B. Rowell,(eds.) Thinking Through Dance. The Philosophy of Dance Performance and Practices, Hampshire: Dance Books.

Cooper Albright, A. (1997) Choreographing Difference, Hanover, NH: Wesleyan University Press.

Crowther, P. (1993) Art and Embodiment, Oxford: Clarendon Press. 
Grau, A. (1992) 'Intercultural Research in the Performing Arts', Dance Research, 10: 2 (Autumn), pp. 3-29.

Hall, S. (1992) 'New Ethnicities', in Donald J. and Rattansi, A. (eds.)

'Race' culture and difference, London: Sage, pp. 252-259.

Jeyifo, B. (1996) 'The Reinvention of Theatrical Tradition, Critical

Discourses on Interculturalism in the African Theatre', in Pavis, P. (ed.) The Intercultural Performance Reader, London: Routledge, pp.149-171.

Ma, L. (2004) 'Wittgenstein’s Language Game and Intercultural

Communication’, Intercultural Communication Studies, 13: 2, pp.100112.

Maclaren, K. (2002) 'Intercorporeality, Intersubjectivity and the Problem of 'Letting Others Be,' Figures and Grounds of the Flesh', Chiasmi International, 4, pp.187-208.

Merleau-Ponty, M. (1962) Phenomenology of Perception, trans. C. Smith, London: Routledge (first published (1945).

Merleau-Ponty, M. (1968) 'The Intertwining-The Chiasm', in The Visible and The Invisible, Evanston: Northwestern University Press pp-130155.

Montes, H. (2011) Interview, London:11 ${ }^{\text {th }}$ June.

Montes, H, Saxon , D. and Sharp, B. Interview, London: $11^{\text {th }}$ September , 
Moreland, J. (1998) 'For Itself and In itself in Sartre and Merleau-Ponty', in J. Stewart.(ed.) The Debate Between Sartre and Merleau-Ponty, Evanston, Illinois: Northwestern University Press, pp.16-24.

Mulvey, L. (1975) 'Visual Pleasure and Narrative Cinema', Screen, 16: 3 (Autumn) pp. 6-18.

O’ Regan, J and Noè, A (2001) ‘A Sensorimotor Account of Vision and Visual Consciousness', Behavioural and Brain Sciences, 24, pp. 9391031

Pantiledes, K. (2011) Siobhan Davies Commissions at Barge House, londondance.com . (Wednesday $9^{\text {th }}$ November) Accessed 11 November 2011.

Rowell, B. (2009) 'Dance Analysis in a Postmodern Age: Integrating Theory and Practice' ,in J.Butterworthand L. Wildschut (eds.) Contemporary Choreography: A Critical Reader, London; New York: Routledge, pp.136-151.

Saxon, D . (2011) Interview, London: 6th May.Sharp, B (2011) Interview, London: $9^{\text {th }}$ July.

Sharp, B. (2012) Interview, London: 29 ${ }^{\text {th }}$ March.

Sheets-Johnstone, M. (2009) The Corporeal Turn: An Interdisciplinary Reader, Exeter: Imprint Academic.

Shusterman, R. (2008) 'The Silent Limping Body of Philosophy: Somatic Attention Deficit in Merleau-Ponty', in Body Consciousness: A 


\title{
Philosophy of Mindfulness and Somaesthetics, New York: Cambridge
}

\author{
University Press, pp. 49-76.
}

\begin{abstract}
${ }^{1}$ I am grateful to the artists for their willingness to share their reflections upon their work with me and to them and SDDC for agreeing that material from their interviews can be published.

${ }^{2}$ It is beyond the parameters of this discussion to resolve the question as to whether a distinction needs to be made between the processes of intercultural and intracultural performance. Rustom Bharucha makes the distinction defining 'intracultural' as ' those exchanges within, between, and across regions in the larger framework of a nation' and' 'Intercultural' as the 'exchange of cultures across nations' (1997:31-33) . However, as Bharucha explores, the experience of cultural diversity, often within a small geographical area, points to the processes of intercultural and intracultural performance be ing more complex than these initial definitions suggest. Further ,within the field of intercultural communication, Lin Ma (2009) argues against defining intercultural and intracultural as essentially different forms of communication as this ignores the specificity of the contexts within which communication takes place.Tthe same argument might well be applied to performance.

${ }^{3}$ Montes was born in America and states his ethnicity as 'Hispanic', Sharp is British and Saxon comes from Australia and now lives in France, but all have worked in London for many years.

${ }^{4}$ Aull Davies recognises the importance of recent (poststructuralist) insights revealing the power/knowledge distortions of underlying metanarratives, and aims to draw attention to multiple perspectives. However she is wary of falling prey to an extreme relativism that is ultimately destructive of the attempt to undertake ethnographic research (Aull Davies, 1999: 6-25).

${ }^{5}$ Sharp is aware of drawing on ideas from Heidegger (whose ideas, alongside those of Husserl, informed Merleau-Ponty's work) and quantum physics, not to represent concepts but to play on how he experiences consciousness as interacting with events in the world.

${ }^{6}$ For a detailed analysis of Merleau-Ponty's concept of flesh, its relationship to his earlier work and to the later work of Deleuze see Judith Butler, 2004.

${ }^{7}$ The lack of recognition of how power relationships on a broader political scale have an impact on intercultural practices is the focus of a number of critiques of intercultural theatre. For example see Jeyifo (1996) and Bharucha (1996).

${ }^{8}$ For example Stuart Hall (1992) proposes forms of 'new ethnicities' that look forward to an eventual weakening of boundaries between ethnic groups as multiple differences bring about a whole range of potential self-definitions that challenge essentialist conceptions of 'race'.'
\end{abstract}

${ }^{9}$ Although there is some confusion over its precise definition, dancers tend to use the term kinaesthesia to refer to all the felt sensations relevant to the body in movement. More specifically kinaesthesia may refer to 'a sense of movement through muscular effort' (Sheets-Johnstone, 2009: 164) but is also sometimes understood to include proprioceptive awareness of the body's position in relation to space and gravity

10 The nature and relevance of kinaesthetic empathy and how to account for it without relying on a dualist opposition between inner feeling and outer behaviour is the subject of much debate that I explore in a little more detail in Carr (2013).

${ }^{11}$ Richard Shusterman (2008) suggests this is due to Merleau-Ponty's aim at that time being to argue against scientific and philosophical accounts of human behaviour that are reliant on prior conscious representations.

\section{Images}

Figure 1 LandMark by Deborah Saxon, Henry Montes and Bruce Sharp. Photo by Bruce Sharp

\author{
Figure 2 LandMark by Deborah Saxon, Henry Montes and Bruce Sharp. Photo \\ by Pari Naderi
}


Figure 3 LandMark by Deborah Saxon, Henry Montes and Bruce Sharp. Photo by Pari Naderi

Figure 4 LandMark by Deborah Saxon, Henry Montes and Bruce Sharp. Photo by Bruce Sharp 